\title{
¿SOMOS LO QUE COMPRAMOS? INTERCAMBIOS ENTRE BAUMAN Y ŽIŽEK EN TORNO AL CONCEPTO DE SUJETO DE CONSUMO
}

\author{
Adryan Fabrizio Pineda Repizo* \\ doi: 10.11144/Javeriana.uph35-71.scic
}

\begin{abstract}
RESUMEN
Este artículo presenta una reflexión en torno al lugar de la subjetividad en la sociedad de consumidores, poniendo en discusión dos alternativas: por una parte, la tesis de la identificación entre sujeto y mercancía, rastreable, entre otros, en Bauman, y, por otra parte, la interpretación de Žižek de la subjetividad como un excedente emergente del conflicto con el orden simbólico. El intercambio resultante entre estas alternativas muestra las relaciones constitutivas del sujeto de consumo en la dimensión del deseo, en el margen de la libertad y en el papel de la reflexividad. Finalmente, se plantea la comprensión de la relación entre el sujeto y el mundo material como una performatividad constructiva de la subjetividad.
\end{abstract}

Palabras clave: sujeto de consumo; deseo; libertad; Žižek; Bauman

Universidad Autónoma de Colombia, Bogotá.

Correo electrónico: faospace@gmail.com

Para citar este artículo: Pineda Repizo, A. F. (2018). ¿Somos lo que compramos? Intercambios entre Bauman y Žižek en torno al concepto de sujeto de consumo. Universitas Philosophica, 35(71), pp. 53-75. ISSN 0120-5323, ISSN en línea 2346-2426. doi: 10.11144/Javeriana.uph35-71.scic 


\title{
ARE WE WHAT WE BUY? AN EXCHANGE BETWEEN BAUMAN AND ŽIŽEK ON THE CONCEPT OF SUBJECT OF CONSUMPTION
}

\begin{abstract}
This paper presents a reflection on subjectivity in the context of consumer society, discussing two alternative approaches: on the one hand, the identification between subject and commodity, traceable, among others, to Bauman, and, on the other hand, Žižek's interpretation of subjectivity as an emerging surplus of the conflict within the symbolic order. The resulting exchange between these alternatives shows the constitutive relations of the subject of consumption in the dimension of desire, in the margin of freedom, and in the role of reflexivity. Finally, the understanding of the relationship between the subject and the material world is proposed as a constructive performativity of subjectivity.
\end{abstract}

Keywords: subject of consumption; desire; freedom; Žižek; Bauman 
LA IDEA DE QUE SOMOS SUJETOS DE CONSUmo parece ser un enunciado descriptivo. Es un hecho: participamos ineludiblemente y desde temprana edad en el circuito del mercado en sus diferentes facetas y niveles y pasamos nuestra vida intentando mejorar las condiciones de nuestra participación. En este juego se ponen sobre la mesa todos los procesos y proyectos de acción en los que nos formamos, las elecciones que tomamos y las experiencias sensibles y afectivas con base en las cuales nos definimos. Sin embargo, la idea misma de sujeto de consumo nos plantea un problema de definición: ¿qué significa ser un sujeto de consumo?, ¿cómo se llega a serlo?, ¿qué caracteriza ser un sujeto de consumo? El hecho de ser sujetos de consumo no encubre facetas claves de la vivencia humana: la vida emocional, el lugar de la libertad y la racionalidad, cuya expresión e interacción son esperables en cualquier individuo. Pero, ¿cómo se manifiesta la vivencia humana en la manera de ser un sujeto de consumo? Como una posibilidad de atender a estos interrogantes sin reducciones ni determinismos quiero proponer esta breve reflexión.

La idea de sujeto de consumo no es oriunda de la filosofía, sino de las ciencias sociales. En este campo la noción de sujeto es usada como un hecho dado e indudable, pertinente para la descripción de formas de identificación de los individuos con su entorno (Chaparro, 2006, p. 16). En la filosofía, el concepto de sujeto ha sido un vector de interrogantes centrales en torno a los presupuestos epistemológicos, históricos o éticos de su aplicación. El concepto de sujeto en filosofía es problémico, puesto que, al decir de Deleuze (1991, p. 94), conlleva tanto una función de universalización de la experiencia -en una época en la que lo universal ya no está representado por esencias, sino por actos sobre la propia existencia-, como, a la vez, una función de individuación en el campo de las relaciones e interacciones entre personas que sienten y se transforman, que hablan y son habladas. Estas dos funciones del concepto de sujeto aluden al rango de posibilidades de la experiencia de sí y señalan el lugar de la tensión, del movimiento, del conflicto inherente como el aspecto ineludible y fundamental de la subjetividad, esto es, de las condiciones de existencia en las cuales un individuo 
llega a ser sujeto ${ }^{1}$. Como afirma Jean-Luc Nancy (1991, p. 4), toda posibilidad de existencia es reabsorbida en la idea del sujeto, y esta idea misma nunca es simple, acabada o cerrada en sí misma, a causa del permanente movimiento de tensión entre ser único y ser 'alguien' en el mundo.

De esta manera, abordar una reflexión filosófica en torno a la idea de sujeto de consumo requiere revisar una estrategia de interpretación de la cultura de consumo y del sistema capitalista ampliamente defendida en estudios contemporáneos, a saber, la tesis de que el sujeto de consumo nace de un proceso de identificación entre el sujeto y la mercancía que consume, a tal punto que el sujeto mismo deviene mercancía. Es posible rastrear esta tesis en reconocidas aproximaciones que han hecho carrera desde la década de 1970; en particular resalta la interpretación de Zygmunt Bauman o Michel Maffesoli, quienes no solo defienden la reducción del sujeto a un proceso de identificación, sino que asumen la identificación como un proceso lineal: el sujeto deviene mercancía. Así, pues, Bauman (2010, p. 83) defiende en su texto Vida de consumo que consumir implica invertir en la propia pertenencia social o de clase, esto es, invertir en adquirir las cualidades que el mercado demanda. A su vez, Maffesoli (2007) señala que la lucha por el reconocimiento se ha convertido en una lucha por la pertenencia mediada a través de los objetos con los que puedo expresar mi posición social. En lo que sigue, a fin de plantear unos interrogantes a esta tesis, seguiremos algunos puntos claves de estos autores, en particular de Bauman.

La idea de que en la sociedad de consumidores la subjetividad se reduce a una identificación entre individuo y mercancía parece desestimar dimensiones constitutivas de la experiencia misma y en virtud de las cuales es posible pensar todavía en el concepto de sujeto. Más aún, desestima que lo constitutivo de la

1 El concepto de subjetividad puede remitirse a las condiciones de existencia de conjuntos de individuos que actúan y viven en un mundo simbólicamente ordenado y frente al cual definen, buscan y luchan por satisfacer unas expectativas de vida; lucha que a su vez define y transforma la manera como pueden concebirse a sí mismos. El énfasis se encuentra en la noción de condiciones de existencia. Si la subjetividad ha de entenderse como resultado de relaciones y estructuras sociales que preexisten al sujeto, se plantea entonces la demanda de definir la subjetividad en contexto y conforme a las condiciones de efectuación de dichas relaciones. Es así como hablar de las condiciones de existencia que configuran la subjetividad en el mundo contemporáneo requiere reconocer los modos particulares en que los individuos son definidos en el mundo social, las maneras en que pueden participar y las determinantes de cómo pueden concebirse a sí mismos. 
experiencia no yace en identificaciones directas de los individuos -con mercancías, fetiches, símbolos, instituciones, ideologías, etc.-, sino en las tensiones, conflictos o antagonismos que generan un excedente de significación. Este es el aporte de las reflexiones de Slavoj Žižek sobre el concepto de sujeto, ubicado en las condiciones contemporáneas de existencia de la sociedad de consumidores. En dos de sus textos, El espinoso sujeto y El acoso de las fantasias, Žižek (2007; 2011, p. 8) muestra que dichos antagonismos impregnan todos los estratos de la vida cotidiana y se materializan en los objetos de consumo y sus simbolismos reguladores. Por consiguiente, una revisión de la tesis de la identificación arriba señalada a la luz de la filosofía de Žižek resulta prolífica para aproximarnos a una respuesta a la pregunta: ¿somos lo que compramos?

\section{El deber de ser deseable}

Para iniciar, tomemos por Caso una ReVista de moda que se encontraría en un mostrador. Junto a una modelo joven, bella, esbelta, ataviada conforme a la estación con su vestido de verano y correspondientes accesorios, aparece el siguiente enunciado: "este verano deberías tener, sí o sí, un vestido off-theshoulders. Enseñar así los hombros es el nuevo escote, palabra de honor, y resulta mucho más femenino y sofisticado. Porque lo sutil es mucho más sexy" (Vives, 2016). ¿Qué encuentra una mujer en esta imagen? ¿Qué despierta en su interior? Aparece aquí un deber de asociar consigo misma un modo de verse, cuyo resultado es una forma de ser y que incluso tiene una justificación principalmente emocional y afectiva: el ser sexy como un valor en sí mismo, como algo deseable per se. Solo que este valor debe ser expresado de una manera particular: mostrar los hombros bajo el sol del verano es sutil, ocultar el resto es sexy. Las emociones se materializan en lo visible del vestido, el juego del cabello y en los accesorios que lo exaltan, de manera que si quieres ser sexy esto es, sí o sí, lo que debes tener. Lo curioso de la moda es que nunca propone adquirir ese vestido particular que se ve en la fotografía, sino su forma, su combinatoria, su contexto, su visibilización y reconocimiento, es decir, la manera de ser a través elementos como los anunciados en la imagen y el enunciado. Con ello, las emociones allí materializadas, susceptibles de universalización para cualquier mujer, se encuentran sustituidas por el significante singular del tipo de vestido y su escenario. De esta manera, 
se fomenta la transición del deseo: a través de lo singular es posible alcanzar ese universal. Lo que debe quedar del mensaje es el deseo del significante singular a fin de que a través del consumo de objetos similares pueda satisfacerse el prometido estado universalizable. Así, el deseo se convierte en la forma de interacción principal y el vector de las relaciones mismas entre los individuos y sus objetos de consumo -o viceversa, da igual-.

El reconocimiento de esta base significante es lo que ha permitido analizar estas relaciones con base en la tesis de la identificación entre el objeto-mercancía y el sujeto. Como ya mencionamos, esta lógica supone que el individuo encuentra en el simbolismo de los objetos -vestido, accesorios, brisa marina y entorno veraniego- una forma de ser con base en la cual dar lugar a un proceso de identificación -ese es el tipo de mujer que deseo ser, que soy, que dejaré de ser una vez acabe la temporada-. La cuestión no yace, empero, en la actividad del consumo mismo, pues consumo siempre ha habido en la historia humana y sus actividades de producción, intercambio y eliminación de objetos. Bauman prefiere hablar de una sociedad de consumidores como aquella que ha añadido a esta dinámica social un vector simbólico: producción, intercambio y eliminación se supeditan a y a la vez determinan la capacidad de querer, desear y anhelar formas de vida a través de la experimentación repetida de las emociones que pueden materializar los objetos de consumo en la vida cotidiana. En palabras de Bauman (2010), se trata de un

tipo de acuerdo social que resulta de la reconversión de los deseos, ganas o anhelos humanos [...] en la principal fuerza de impulso y de operaciones de la sociedad, una fuerza que coordina la reproducción sistemática, la integración social, la estratificación social y la formación del individuo humano (p. 47).

En este sentido, la capacidad de desear es alienada de los individuos y reificada en los objetos de consumo. Así, la posibilidad de ser sexy, ser feliz, ser joven, etc., se encuentra en los objetos. Pero su gratificación no es sino momentánea, pues el deseo no puede desaparecer o el consumo desaparecería, de modo tal que siempre se requerirá un nuevo objeto para el mismo deseo. En estas condiciones, los individuos viven sus emociones con base en deseos insaciables que demandan una satisfacción imposible de realizar.

A la luz de este fenómeno no es difícil encontrar que la explicación de la subjetividad con base en un proceso de identificación no puede ser simplemente 
desestimada. La permanente búsqueda de satisfacción de los deseos, siendo estos dirigidos por las relaciones entre el significante singular de moda y la promesa universalizable de una forma de ser, plantea la idea de que el sujeto no es más que el resultado del proceso de identificación entre el deseo vacío y el objeto deseado. De ahí la lectura que Bauman o Maffesoli -incluso, previamente, Baudrillard (1991) - plantean cada vez que encuentran en la reversibilidad de la relación significante-significado la posibilidad de identificar el sujeto con una versión material de la mercancía.

Empero, estimo que es posible atender al proceso descrito sin necesidad de saltar tan rápidamente a esta conclusión. La lógica de la identificación concibe desear, querer o anhelar como acciones receptivas. El deseo es el deseo de adquirir. Pero es posible cuestionar esta premisa. El deseo como adquirir se encuentra activo en el orden de lo simbólico, reacciona ante y reproduce las relaciones constitutivas de su forma vacía. Sin embargo, el sujeto no vive solamente la ausencia de satisfacción final, sino que en el proceso mismo de desear, de seguir la corriente, encuentra otra matriz constitutiva que en sí misma es productiva. Hay una faceta de desear, querer o anhelar que deja de ser receptiva y ejerce un carácter productivo. Puede que las lectoras de la revista de moda encuentren -o nouna desazón final al no alcanzar la emoción esperada: la percepción de su propia sutileza y sensualidad en el vestido. Pero el proceso mismo de desear y vivir el deseo, de armar su experiencia, de gozar su línea de escape armando en sí misma la imagen de su sensualidad es una experiencia auto-constitutiva de su subjetividad que se instaura en las mismas condiciones de existencia como consumidora de moda. Žižek (2007) aborda esta perspectiva cuando traza una diferencia entre el sujeto del deseo y el sujeto de la pulsión:

[...] mientras que el sujeto del deseo se basa en la falta constitutiva (existe en cuanto está en busca del objeto-causa faltante), el sujeto de la pulsión tiene su fundamento en un excedente constitutivo: en la presencia excesiva de alguna Cosa intrínsecamente "imposible" y que no debe estar allí, en nuestra realidad presente: la Cosa que, por supuesto, es en última instancia el sujeto mismo (p. 329).

La moda no solo se alimenta de deseos frustrados, tal como lo considera Bauman desde la lógica de la identificación; requiere un excedente de placer que resulta 
de la vivencia del desear esa forma de ser. Por ello es más atractivo para la mujer que lee la revista sostener la búsqueda de estar a la moda y vivir la pulsión que le lleva a perseguir ese fantasma que adquirir uno u otro vestido particular. Esto se debe a que la pulsión no remite al objeto ausente, sino al repliegue del sujeto sobre sí mismo como objeto de acción, alteración, transformación y satisfacción.

Que este sujeto de la pulsión conlleve un inevitable antagonismo no implica su imposibilidad. Por el contrario, es precisamente en el conflicto entre deseo y pulsión en el que se pone en marcha la subjetividad. Así, pues, resulta estrecha la mirada de la identificación que solamente atiende al resultado insatisfactorio del deseo, olvidando que la dirección hacia el objeto deseado, el objeto de consumo, siempre implica un repliegue hacia sí mismo. El sujeto deseado y significado para el que el objeto de moda es significante, es también él mismo significante de su propia imagen de sí; y el conflicto entre el sujeto de consumo y esta imagen es exactamente lo que mantiene viva su subjetividad -en caso contrario, no sería sino un objeto más entre lo que hay y, en consecuencia, tampoco requeriría consumir-. Si esto es cierto, y el sujeto de la pulsión yace en el conflicto constitutivo del desear y no en la unidad vacía del deseo, entonces esa faceta del sujeto es una que es excedente respecto a la identidad simbólica buscada. Esta identidad simbólica permanece en el marco de las relaciones entre el conjunto de los significados de formas de ser que, por ejemplo, ofrece la moda y el sujeto de consumo como singular significante del mismo. Empero, siempre existe una distorsión entre el significante singular y los posibles significados; en otras palabras, puede haber una polivalencia de significados para el mismo significante, tal que la identidad simbólica pueda cambiar.

Hay, en la interpretación que Žižek (2011) hace de Lacan, una idea que puede dar cuenta de este fenómeno, a saber, lo que él llama "atravesar la fantasía". La fantasía, por una parte, se ubica en el registro de la ideología y, en consecuencia, es una estructura intersubjetiva de narración de la propia existencia que ocluye el antagonismo². En otras palabras, busca cerrar la identidad simbólica. La fantasía constituye el deseo y enseña cómo hay que desear, de manera que provee las

2 "El deseo surge cuando la pulsión queda atrapada en la telaraña de la ley/prohibición, en el círculo vicioso en el que 'es preciso que el goce sea rechazado para que se lo pueda alcanzar en la escala invertida de la ley del deseo' (Lacan, 2007). La fantasía es la narración de esa pérdida primordial, en 
distintas posiciones subjetivas entre las que el sujeto puede desplazarse. La idea de atravesar la fantasía, por otra parte, remite al reconocimiento del antagonismo fundamental que la fantasía oculta como resultado final y, con ello, a la posibilidad de generar un repliegue sobre la norma simbólica misma para vivirla como si, de hecho, fuera una elección propia. Se trata, en palabras de Žižek (2011), del "acto de interpretar la pura formalidad (la proposición que debe ser rechazada) de forma literal -el acto de considerar la elección forzosa como una verdadera elección-” (p. 39). Cuando no se cede a la frustración de la imposibilidad de adquirir el simbolismo de la moda, la prometida forma de ser, sino que se goza el síntoma de la pulsión que lleva a vivenciar la propia experiencia de sí, el sujeto se hace reflexivo en un sentido casi hegeliano, pues mantiene activa la confrontación con el objeto de deseo imposible, pero negando la negación narrativa de la fantasía: repliega la identidad simbólica en un retorno reflexivo del orden simbólico sobre sí y para sí. El agente de este fenómeno es precisamente el carácter productivo del sujeto de la pulsión. $\mathrm{O}$, en otras palabras, el vestido de verano deseado ya no es solo signo de la ausencia sino que es significante del conflicto que impulsa la pulsión de la mujer a ser sexy y sutil de manera singular, por ejemplo, exacerbando su vestuario, realizando su propia combinatoria, enfatizando la frontera entre lo sutil y lo indiscreto. Mientras que el deseo es reprimido en el orden de la fantasía definiendo la posición de sujeto que corresponde (la mujer que ve la fotografía, sueña y dice "jamás tendré la figura para ese vestido"), el acto pulsional de atravesar la fantasía da vuelta a la norma para ratificar la propia vivencia (la mujer que sale mostrando sus hombros y ombligo y disfruta de exponer sus gorditos al sol). La pulsión interpreta lo que debe ser oculto como directriz que pervierte la norma de la fantasía y con ello dinamiza una tensión constitutiva de la subjetividad que no se agota en los simbolismos de la sociedad de consumidores.

\section{La labor de devenir presencia}

Esta EXPERIENCIA DEL SUJeTO DE LA PULSIÓn deja en punta un interrogante fundamental a la hora de analizar la idea del sujeto de consumo: ¿este

la medida en que escenifica la elaboración de esa renuncia, el surgimiento de la ley. En este sentido, la fantasía es la propia pantalla que separa al deseo de la pulsión" (Žižek, 2011, p. 43). 
sujeto ejerce una voluntad libre en el circuito de consumo? Este es un punto crítico para los ponentes de la tesis de la identificación entre sujeto y mercancía, con base en la cual han mostrado una serie de lastres sobre la libertad, en particular la libertad de elección. Según Bauman, la libertad en la sociedad de consumidores constituye un bien más que una propiedad del ser humano. Es algo que se adquiere, se gana, se aplica y construye. Esto se evidencia en enunciados que atraviesan diversos escenarios de participación consumista como los centros comerciales. Salir de compras es disponerse a ser bombardeado por una multitud de ofertas diversas sobre diferentes objetos de temporada. Con base en esta multiplicidad se ratifica la demanda de elección hacia los individuos.

De ahí la diferencia con el sentido moderno de libertad. Para Kant, el ejercicio de la libertad se reflejaba, no en la posibilidad de elegir, sino en la obligación de regirse a sí mismo, de ser autónomo. El imperativo categórico kantiano es una forma de la razón práctica orientada sobre sí misma, cuyo producto es la legitimación del deber para sí y para con otros. La cuestión radica en que este sentido de libertad se supone constitutivo del sujeto en un sentido a priori. Por el contrario, cuando la libertad se entiende como libertad de opciones, subyace la obligación de elegir como forma constitutiva del sujeto. La negación de elegir es la ausencia de libertad y, en consecuencia, la autodestrucción del sujeto. Asumiendo esta perspectiva, no es difícil reconocer que una versión de la libertad como la kantiana resuene ajena, coactiva, añeja; pues, en una sociedad de consumo, la única opción que no cabe es la de elegir libremente regular o ceñir la propia capacidad de elección. Así, la opción de salir de un centro comercial sin un paquete en la mano que ratifique la propia libertad, el ejercicio y poder de elección, es vivenciada como frustrante decepción o "pérdida de tiempo"; como si algo de sí mismo se hubiera perdido en esa salida.

Volviendo a Bauman, la perspectiva de la identificación tiene la virtud de resaltar puntos importantes. Por una parte, resulta llamativo que la obligación de elegir esté ineludiblemente ligada a la capacidad adquisitiva o de endeudamiento. Siempre el resultado de la elección es una materialización de la subjetividad a través de los zapatos, carteras, vehículos, accesorios, dispositivos, etc. En una línea familiar, Žižek (2011) plantea el siguiente ejemplo: 
[...] un hombre que viva en una gran ciudad y sea propietario de un Land Rover no solo vive de forma sensata y "con los pies en la tierra"; sucede más bien que es propietario de un coche como ese para señalar que su vida se rige conforme a una actitud sensata y "con los pies en la tierra" (p. 8).

La idea de que compramos por utilidad es tan común como ciega e ingenua. La utilidad misma de un objeto es relacional, nunca es una propiedad del objeto, y está ligada a la vida cotidiana. En consecuencia, la utilidad es siempre reflexiva y entraña una significación subjetiva que es, por ende, ideológica. Los objetos de consumo son útiles para ratificar, renovar o modificar nuestra posición de sujetos en la sociedad: el estrato, el grupo social, la posición laboral, etc., de un modo que supone incluso, al decir de Bauman (2010), la "distribución de la estima o el estigma social, así como la cuota de atención pública” (p. 78). Por ello, la lógica de la identificación nuevamente ofrece una explicación del fenómeno: yo soy lo que las cosas que tengo dicen (a otros) de mí, pues al identificarme con los simbolismos de los objetos ellos terminan por hablar en mi lugar. La elección entonces consiste en adquirir suficientes artilugios y recursos para no tener que dar cuenta de uno mismo.

Bajo esta óptica, por otra parte, la subjetividad es, en suma, fetichizada. Si la libertad ha sido descentrada y desplazada sobre el consumo y este reproduce formas de adquirir maneras de ser, entonces la subjetividad es algo que no le pertenece ya al sujeto mismo, sino a los significantes que los objetos construyen por él bajo la forma de estilos de vida o personalidad. Pero estos significantes no solo sustituyen la presencia del individuo, sino que, además, se hacen fines en sí mismos, esto es, no hay otra manera de ser sensato sino a través de la $4 \times 4$ Land Cruiser que lo materializa. Žižek (2011), incluso, va un paso más allá en este asunto de la fetichización cuando afirma que esta pertenece a la estructura del orden simbólico mismo:

[...] un burgués normal y corriente no solo (mal)interpreta el dinero como un objeto material dotado de la propiedad mágica de funcionar como equivalente de todas las mercancías [...]. Lo que [...] no advierte es mucho más fundamental: es que el dinero no es precisamente una simple señal de las relaciones interpersonales, sino que surge como la materialización de la institución simbólica, en la medida en que dicha institución es irreductible a la interacción directa entre "individuos concretos" (p. 115). 
No se trata de que el dinero sea el fetiche por excelencia, sino de que en la red simbólica en la que tiene lugar el juego del consumo - del "intercambio simbólico", diría Baudrillard (1991)-, objeto de consumo y sujeto consumidor son entidades reificadas en sí mismas que garantizan el funcionamiento de la institución simbólica. De ahí que los sentimientos más íntimos sean susceptibles de materialización por medio de la exteriorización radical, tanto en los significantes que cada individuo persigue de manera activa, como en los objetos que lo sustituyen y lo dejan en forma pasiva. Esta doble sustitución (por el significante y por el objeto) es, según Žižek (2011, p. 125), la forma del sujeto descentrado.

Queda, empero, el interrogante abierto: ¿esto es todo a lo que puede aspirar el sujeto en términos de libertad? ¿Es suficiente afirmar y reiterar la alienación consumista como la única opción de la voluntad? Desde la óptica de la tesis de la identificación habría que dar una respuesta afirmativa. Sin embargo, la experiencia de construcción de la subjetividad para los individuos no acaba en el centro comercial. Llama la atención que cuando pensamos en el consumo el énfasis suele quedarse en el momento de la relación entre producción y adquisición. Pero ¿qué pasa con los objetos después de ser adquiridos? El circuito del objeto de consumo tiene al menos dos etapas más: la apropiación y la eliminación. Pensar en la apropiación implica ponerse en el lugar de la experiencia íntima y vivencial. Todo individuo que visita un centro comercial se ve abocado a tomar la posición de comprador y con ello reproducir la lógica que hasta ahora hemos descrito. Pero, al salir de allí y llegar a su destino, enfrenta una serie de interrogantes personales que exceden la identificación simbólica prevista a la hora de adquirir el objeto: ¿y ahora dónde ubico este televisor? ¿Estas cortinas salen con el vestuario? ¿Qué pasa con este mueble que no tiene lugar? ¿Debo girar la sala entera para que se vea el florero? Un ejercicio reflexivo empieza a interpelar al individuo y lo obliga a poner en suspenso la expectativa de sustitución.

El conflicto que aquí se vislumbra se puede evidenciar por la distinción entre dos versiones de la subjetividad. La tesis de la identificación entiende el sujeto conforme a su posición en el orden simbólico, pero la experiencia de la apropiación es la de un excedente que se ve obligado a contravenir, al menos momentáneamente, dicha posición. Es similar al vacío que deja el sujeto foucaultiano. Para Foucault (2013), el sujeto es efecto de las medidas de disciplina y control que lo forman o producen. La ley, las normas, los reglamentos, el acto confesional 
involucran prácticas que definen y reproducen relaciones de poder en las que cada uno es formado como sujeto. Pero lo que Foucault desestima es lo que hace cada uno con esas medidas disciplinares en la ejecución de las prácticas. Este es el señalamiento que Žižek (2007) hace a Foucault: "el auto sondeo confesional no solo desentierra nuevas formas de sexualidad, sino que la actividad confesional en sí se sexualiza, da origen a una satisfacción propia" (p. 270). No se trata, sin embargo, de la búsqueda de un afuera del sistema dentro de las prácticas: el rebelde que organiza su movimiento para derrocar al Estado realiza su acción dentro de la lógica del orden simbólico que lo lleva a reestablecer el Estado. En el marco del consumo, el sujeto no se libera de la alienación fetichista buscando formas alternativas de consumo orientadas a afirmar una salida eco-orgánica o anárquica, pues la ratificación de estos opuestos reproduce el significante que pretende negar. Este es el conflicto entre el contenido enunciado y la posición de enunciación que pertenece de antemano al orden simbólico. Por el contrario, se trata de encontrar dentro del mismo orden un efecto suplementario, o "un excedente de resistencia” que esté contenido en la propia reproducción del poder. Según Žižek (2007),

[...] esta es la razón por la que falta en Foucault el concepto apropiado del sujeto: el sujeto es por definición un excedente sobre su causa, y como tal surge con la inversión de la represión de la sexualidad en sexualización de las propias medidas represivas (p. 274).

Tal es el drama que puede vivir un individuo que enfrenta la pasividad de los objetos adquiridos, esto es, todo el conjunto de objetos por sí mismos no alcanza a decir lo que quiere que digan sobre él. En "¡esto ya no va bien aquí!, ¡debo volcar la sala entera!, iya no disfruto de mi habitación... o de mi cuerpo!”, etc., se expresa ese excedente en el que la apropiación del objeto se vive como conflicto entre las expectativas adquiridas, compradas en el centro comercial, y el espacio informe que demanda, en palabras de Benjamin (2004), dejar marcadas las "huellas" de los habitantes.

Este cuestionamiento no se puede atender desde la óptica de la identificación del sujeto consumidor con el objeto de consumo y, en consecuencia, es lo que muestra la falta de radicalidad al asumir la subjetividad no como unidad, sino como proceso. Probablemente la expresión más afortunada de lo que es el sujeto 
de consumo en términos del ejercicio de su libertad pueda corresponderse con las palabras de Jean-Luc Nancy (1991). Este autor define el ejercicio de la libertad no como una propiedad del sujeto, sino como la experiencia misma de llegar a ser, de "devenir presencia" (p. 6). El punto es que devenir presencia es una tarea inacabable, pues depende de un conflicto reflexivo entre el simbolismo adquirido y la demanda de las huellas. El simbolismo sustituye unidades acabadas, todas ellas dentro de la misma red de significación; la demanda de dejar huella no puede ser unidad y es insustituible. Es el acto el que es demandado, no el resultado.

Por ello, yace aquí una versión distinta de la subjetividad en la que esta no emerge sino hasta que la posición materializada y adquirida en los objetos es a su vez negada dialécticamente en la experiencia vivida. Así, la antidialéctica de Foucault requiere precisamente un giro autorreferencial hegeliano entre el en sí y el para sí o, en otras palabras, la negación de la negación. Esta es la crítica que Žižek realiza a Foucault y de la cual extrae la noción de subjetividad como estado activo de conflicto. Para Žižek (2007), la negación de la negación es el pasaje del estado A al estado B, en la medida en que la negación de A niega su posición "sin abandonar los límites simbólicos, de modo que debe seguirla otra negación, la cual niega el espacio simbólico común de A y su negación inmediata” (p. 81). Es en este giro reflexivo de la negación de la negación en el que Žižek (2007) encuentra el lugar del sujeto, pues

[...] socava la oposición entre el objetivismo ingenuo y el subjetivismo trascendental: no tenemos la "realidad objetiva" dada de antemano, con una multitud de perspectivas subjetivas en las que dicha realidad aparece distorsionada, ni tampoco su contrapunto trascendental, el Sujeto unificado que abarca y constituye el todo de la realidad; lo que tenemos es la paradoja de sujetos múltiples incluidos en la realidad, insertados en ella, y cuyos modos de verla también la constituyen (p. 87).

La subjetividad nunca es acabada, sino que está viciada por la perspectiva que tiene de la realidad; pero, además, la subjetividad no es un Absoluto, pues este no es más que el movimiento reflexivo en sí mismo.

Es en esta reflexividad constitutiva del sujeto donde emerge el margen de libertad: la crisis de la apropiación confronta el orden simbólico con el vacío de lo real de la propia existencia; en otras palabras, el sujeto desea la posición que 
le ofrece el objeto de consumo, el estatus y simbolismo de la Land Rover -sobre esta otredad se externaliza-, pero llegado el momento de hacer algo con ello en el espacio vital cercano debe incorporarlo reflexivamente, apropiarlo en la búsqueda de unidad de su propia vida y tomar el riesgo del éxito o fracaso de su acción -hacerla para sí-. De esta manera, el orden simbólico se convierte en el trasfondo necesario para el espacio de la libertad, que se ejerce en el instante de la negación de dicho orden. En consecuencia, no se trata aquí de un proceso de identificación, sino, al decir de Žižek (2007), de un proceso de "autodiferenciación, que pone su otredad y después se la reapropia” (p. 100) en la reflexión. Si la subjetividad supone una identidad, no es más que una identidad especulativa. Lo cual quiere decir que la subjetividad es material en tanto externaliza el proceso reflexivo, conflictivo, que sostiene la relación entre el sujeto (quien encuentra en los objetos de consumo la materialización del modo de ser que desea) y el acto reflexivo de apropiación (esta acusa la necesidad de convertir ese simbolismo en algo para sí: en un aspecto singular y personal que demuestre su diferenciación respecto del simbolismo que en primer lugar motivó la adquisición). Podríamos llamar a este fenómeno una reflexividad diacrítica: es el caso de la mujer que no tiene qué ponerse porque los nuevos zapatos distorsionan todo su vestier, del hombre que reajusta toda la sala para que el nuevo televisor tenga la potencia esperada, del niño que debe aprender a jugar fútbol porque la camiseta de su héroe le compele. Puede ser el caso que ella nunca encuentre la combinación adecuada, que el televisor siempre estorbe y que el niño termine odiando jugar fútbol, pero hubo un proceso constitutivo de subjetividad que demandó un ejercicio de la libertad, incluso en el transcurso que llevó a la frustración -y a la necesidad de repetir la experiencia-.

\section{De una reflexividad diacrítica}

LLEGADOS A ESTE PUNTO, el consumo no puede ser visto como una mera tarea de adquisición de cosas. Estimo que es cada vez más claro que el orden simbólico de la sociedad de consumo, en efecto, conforma las condiciones de existencia en las que la subjetividad, entendida como un dinámico conflicto constitutivo de los individuos, tiene lugar y tiene excedencia. En consecuencia, si atendemos, finalmente, a esta faceta de reflexividad, observamos que la acción de los individuos 
en la vida de consumo tampoco es, como afirma Bauman (2010, p. 77), una mera tarea irreflexiva e irracional producto de una manipulación mercantil. De hecho, podría decirse que el éxito de la vida de consumo yace precisamente en el margen de intensidad de la tensión que invita a hacer de la propia vida y subjetividad un proyecto de permanente construcción. Este proyecto no desestima la alienación voluntaria de los individuos a los preceptos del orden simbólico; pero, a la vez, este depende y es frágil ante el excedente constitutivo de subjetividad que se le escapa y lo confronta permanentemente. Mientras que para Bauman (2010) la vida de consumo implica "hacer de uno mismo un producto vendible [...], una tarea del tipo 'hágalo usted mismo'” (p. 84), diríamos que la subjetividad implicada en la sociedad de consumidores es una que emerge de la posibilidad de encontrar vivencias de ruptura de la identificación simbólica. El individuo, su cuerpo, su apariencia, su entorno inmediato y grupo social se convierten, en esos instantes, en materia de experimentación vivencial. Resulta interesante la manera en que los individuos desmoldan la utilidad prevista de los objetos de consumo y los alteran, invierten, transforman en un barroquismo personalizado: en la medida de cada posibilidad, resulta tan expresivo el exceso de accesorios en el cuerpo de una mujer, en el interior o exterior de un vehículo, en las paredes de una habitación, como la reducción de los mismos al mínimo; en ambos casos, jugando juegos de autodiferenciación del individuo, es puesta en tensión su posición de sujeto y ejecutada su subjetividad. Puede que el mercado posteriormente encuentre en dichos gestos materia de explotación y producción. Las tendencias emergentes de la cultura popular, por ejemplo, la 'customización' del vehículo o de la vestimenta, suelen convertirse en productos categorizables de mercadeo en las grandes plataformas -hoy se puede ser rebelde suburbano a través de una compra en línea-. Pero el momento creativo original en el que la referencia reflexiva centró la atención en una distinción de la propia vivencia apropiando y desviando los simbolismos comunes constituye en sí un momento creativo constitutivo de la subjetividad: a esto nos referimos con reflexividad diacrítica.

Suele ser incluso el caso que estos momentos creativos no pueden evitar ser vistos como parias frente al simbolismo de moda, ya por su exotismo, ya por su simpleza, rebajándolos a un estado barroco deplorable. Pero, como afirma Maffesoli (2007), lo barroco es condición de la identidad contemporánea: 
Esta es la particularidad del barroco: mantener juntos elementos perfectamente heterogéneos. [...] Ciertamente es posible poseer cosas, pero poco a poco uno se ve poseído por ellas. Y es esta "posesión”, común para la gran mayoría, lo que funda, de manera detallada, la comunidad humana (p. 168).

De esta manera, es necesario darle el lugar que corresponde a la lógica de la identificación. El esfuerzo no ha consistido en desacreditar esta interpretación de la subjetividad en el contemporáneo mundo del consumismo; por el contrario, se trata de ubicarla en un escenario que, estimo, resulta más complejo. Para Maffesoli (2007), "la lógica de la identificación pone en el escenario a 'personas' con máscaras variables, tributarias del o de los tótems emblemáticos con los cuales se identifican" (p. 16), en virtud de lo cual encuentran la posibilidad de "llegar a ser" en la pérdida de sí dentro de la tribu, la comunidad o la masa. En muchas ocasiones participamos de la sociedad de consumo para sentir el alivio de desaparecer y hacer desaparecer los pesos de las responsabilidades individuales. Pero al otro extremo de esta experiencia se encuentra el razonamiento dirigido a resolver quién soy, quién quiero ser y cómo lo puedo ver. Estas son preguntas que ya no se responden con una introspección cartesiana o existencial; por el contrario, requieren visibilidad, materialización: esa es precisamente la tarea que los objetos de consumo realizan para el sujeto.

Así, un nuevo antagonismo queda señalado entre la identificación comunitaria y la reflexividad diacrítica. Este antagonismo es el lugar de la subjetividad, pues, como diría Nancy (1991, p. 6) siguiendo a Hegel, el sujeto es aquello capaz de mantener en sí mismo sus propias contradicciones. Con esto hay que evitar caer en la idea de que la subjetividad se encuentra solo del lado de la reacción del oprimido: la mujer que masculiniza su apariencia para escapar de las coordenadas heterosexuales, el homosexual que se transvierte para radicalizar su identidad, el afro que exagera su negritud para defender sus raíces, o el punk que se abarrota de todo lo que su padre le ha prohibido. En estos casos, como ya sabía Hegel, cada identidad no es sino una ratificación de la posición del opresor que buscaba eludir o minar, pues es una identidad definida por la oposición al otro. Por el contrario, nos referimos aquí a una vivencia más primaria, o mejor infantil: el juego del niño que transforma la cosa en espada, en máquina, en nave, en océano y, al hacerlo, lo transforma a él en un héroe, villano o aventurero. El juego es un juego de co-construcción entre el sujeto y el uso del objeto; juego que se 
traslada, en diferentes intensidades, a la moto del soltero, al sedán de la ejecutiva, a la silla del abuelo. El objeto de uso se convierte así en un vector en el que confluyen la necesidad de identificación comunitaria y la de reflexividad diacrítica.

La posibilidad de que la vida singular misma pueda ser concebida como un proyecto creativo del que emerja el sujeto supone un ejercicio de racionalidad práctica. La vivencia de la apropiación de los objetos de consumo pasa por un razonamiento práctico que legitima la adopción del simbolismo (materialización en el otro del en sí); el retorno a la vivencia propia y el vacío identificado en la concepción de sí (apropiación reflexiva del otro en el para sí); y la unificación de una forma de sujeto en un estado autodiferenciador (posición de sujeto emergente). Un joven soltero encuentra en la moda de una moto café racer un deseo de forma de vida estilizada, libre, juvenil y exclusiva que busca ser satisfecho en su adquisición. La llegada a casa de la moto se confronta con las paredes de siempre, el espacio reducido y la realidad de una vida rutinaria y dependiente; se requiere adoptar una apariencia y concepción de sí coherente con el estilo en el contexto particular individual, por lo cual se debe a la vez invertir en la adecuada vestimenta casual no deportiva, el nuevo corte de cabello a la moda, los accesorios correspondientes en indumentaria e instrumentos de trabajo. La vida estilizada, libre y exclusiva impone un razonamiento práctico orientado a otorgar coherencia a toda la imagen de sí mismo que se está elaborando - de lo contrario, la exclusiva café racer permanecerá empolvándose en el garaje indefinidamente y acusando diariamente la frustración de aquel sueño-.

Como vimos al comienzo, los deseos son fácilmente frustrables, pero el elemento pulsional que suscita es capaz de convertirse en el factor dinamizador de toda esta experiencia creativa. Es por ello que el razonamiento práctico aquí involucrado no está orientado por un imperativo moral, sino por un imperativo estético: haz de tu vida un proyecto placentero. Este es el imperativo del sujeto consumidor que permite que exceda la superficie misma de la institución consumista. La pulsión como factor dinamizador lleva en sí misma el goce de su seguimiento; el deseo, por el contrario, implica frustración y clausura de la reflexividad. Es en este proceso en el que los antagonismos resultan constructivos, productivos y creativos de la subjetividad.

De esta manera, en el marco de la experiencia que va del consumo a la apropiación, el ejercicio de la racionalidad práctica adquiere la forma de una 
performatividad material de la subjetividad. La clave está en el concepto de performatividad. La estética de la que estamos hablando no se refiere al tópico tradicional de la belleza, sino que remite a la experiencia de lo sensible, lo visible, incluso lo afectivo y lo deseable, en sus diversas manifestaciones. Así, la performatividad remite a la materialización de la subjetividad en la relación que los individuos establecen con los simbolismos de los objetos de consumo y su propia existencia: su ejercicio de devenir presencia.

Judith Butler (2009) nos recuerda que en la performatividad se requiere la reproducción de normas pertenecientes al orden simbólico; de lo contrario carecería de "legibilidad en el espacio social y el tiempo, así como una relación implícita hacia los otros [...] que está condicionada y mediada por normas sociales" (p. 333). Pero, a la vez, esas normas entran en crisis al ser reelaboradas en la performatividad misma. El conflicto que esto genera es fuente tanto de inclusión como de exclusión de procesos de identificación social. "La performatividad tiene completamente que ver con 'quién' puede ser producido como un sujeto reconocible, un sujeto que está viviendo, cuya vida vale la pena proteger y cuya vida, cuando se pierde, vale la pena añorar" (p. 335). Otra manera de decirlo es que lo que escapa al consumo es el vínculo íntimo entre lo que el objeto significa como lujo y lo que 'hace' para hacer visible una forma de subjetividad que me una con otros y con el mundo.

El performativo no es meramente un acto usado por un sujeto pre-dado, sino es una de las poderosas e insidiosas maneras por las cuales los sujetos son convocados como seres sociales, inaugurados en la socialidad por una variedad de interpelaciones difusas y poderosas. En este sentido, el performativo social es una parte crucial no solo de la formación de sujetos, sino de la continua lucha y reformulación política del sujeto. En este sentido, el performativo no solo es una práctica ritual: es uno de los rituales influyentes por los cuales los sujetos son formados y reformulados (Butler, 1999, p. 125).

La performatividad está en el orden del significante, cuyo significado es construido en el proceso reflexivo del individuo. Ello es lo que alienta la necesidad permanente de renovar el repertorio de objetos, esto es, de renovar la identificación que el mundo de los objetos de consumo no puede acabar. Así, cuando observamos una sala con su mobiliario y decoración, tendríamos que reconocer 
que lo que habita esa sala es un sujeto en composición. La formación de la subjetividad a través de la performatividad material tiene entonces una doble faz: la del acto de materialización de la reflexividad y la del proceso de identificación. La identificación reproduce desde el orden simbólico de base el ejercicio de interpelación ideológica que da sentido a cada posición de sujeto. Un mobiliario ostentoso da cuenta de una forma de ser y valorar el lujo y el poder adquisitivo, así como de establecer una distancia entre quien lo posee y quien no. Pero la performatividad no acaba en la interpelación. El uso de los objetos muestra que lo performativo se caracteriza por la tensión entre la reproducción de la norma y la emergencia de un excedente de significación generado por el conflicto con lo reproducido. Por el hecho de que, en términos butlerianos, la "citación" del enunciado performativo es tanto reiteración de la norma como alteridad de lo repetido: "la variabilidad del contexto del que depende el performativo conlleva siempre la posibilidad de lograr un uso desviado de lo repetido. La fuerza del performativo excede la mera repetición de lo establecido" (Boccardi, 2010, p. 28). Lo repetido es ya otro signo que no puede garantizar la determinación del performativo.

Esto indica que junto a la citación de las normas aparecen una serie de acciones que modulan la manera como cada sujeto personaliza su habitar en el mundo. Se trata de una "táctica”, según la expresión de Michel de Certeau (2000, p. 44), orientada a redirigir las fuerzas del orden simbólico en "maneras de hacer" lo cotidiano y, con ello, devenir una presencia autodiferenciadora frente a dicho orden. Puede que en una sala del hogar de un anciano la multiplicidad de objetos de lujo no simplemente ostente un poder económico otrora alcanzado, sino que a la vez configure una red de monumentos a una vida pasada que se contradiga con la precariedad actual. La performatividad tiene como base pulsional el proceso de identificación, pero este se ve subvertido por la reflexividad diacrítica que demanda una autodiferenciación del individuo: ser un yo capaz de hacer algo que marque su diferencia. Por ello, al decir de Maffesoli (2007, p. 260), esta demanda de autodiferenciación se traduce en la composibilidad de una atmósfera estética capaz de segregar un "aura", que en la sociedad de masas ya no le pertenecería a la obra de arte, sino a las diversas capas de lo cotidiano. El diagnóstico de Benjamin sobre la obra de arte es revertido en la cotidianidad, pues son precisamente esos objetos reproducibles técnicamente los que en la 
sociedad contemporánea son usados para materializar el conflicto que señalamos al inicio de este texto entre lo universal y lo singular y que constituye, según Deleuze, la base ontológica del sujeto. Ver cualquier escenario de un hogar es siempre observar las tensiones que emergen en el continuo proceso de identificación, de consolidación y de renovación del sujeto, de negociación entre la sujeción a un orden simbólico y la subversión del mismo mediante una reflexividad táctica, pulsional y práctica. El uso del performativo -la materialización de la subjetividad- supone la reproducción cultural y re-creación del usuario al interior de la cotidianidad (sujeción y subversión, dos poderes constitutivos de la subjetividad, según Butler).

\section{Conclusión}

En CONTRASTE CON LA IDEA ACOSTUmbRada de que estamos ante un sujeto en el momento en que un ente muestra signos de vida interior irreductible a la exterioridad, la reflexión en torno a las condiciones de existencia en la sociedad de consumidores muestra la opción de externalizar la subjetividad en su materialización performativa: allí donde los objetos hablan y crean márgenes de subjetividad. Los conceptos tomados de Žižek, puestos en contraste con algunos elementos de Bauman, han permitido dirigir la atención hacia las complejas relaciones constitutivas de la subjetividad que exceden la lógica de la identificación y que, con el apoyo de Butler, adquieren la forma de una performatividad estética. El orden simbólico siempre resultará plenamente inaccesible al sujeto interior, siendo este interpelado constantemente frente a cada posible desviación: "debes ser de esta manera, debes tener estas cosas". Pero si ese fuera el todo de la subjetividad, no cabría encontrar los márgenes de creatividad y transformación individual que subvierten el dominio ideológico en la reflexividad. Antes bien, las tensiones y conflictos emergentes entre la inaccesibilidad y las interpelaciones constituyen el lugar de la subjetividad, demandan un movimiento generador de multiplicidad y resistencia en la vida cotidiana que se expresa en una serie en permanente construcción de múltiples posiciones de sujeto en conflicto y variación. De ahí que el sujeto sea el resultado emergente de un proceso reflexivo y conflictivo que se expresa de manera estética y creativa. Es en la dimensión estética de la vida -y lo más cotidiano de 
la misma, en su encuentro con el mundo material- donde la vida emocional, la voluntad personal y la reflexividad de la existencia pueden devenir una presencia que sirva como punto de partida para establecer un modo de ser para sí y para otros.

Referencias

Baudrillard, J. (1991). Crítica de la economía politica del signo. México: Siglo XXI.

Bauman, Z. (2010). Vida de consumo. Buenos Aires: Fondo de Cultura Económica.

Benjamin, W. (2004). El libro de los pasajes. Madrid: Akal.

Boccardi, F. (2010). La performatividad en disputa: acerca de detractores y precursores del performativo butleriano. Aesthethika. Revista Internacional sobre Subjetividad, Politica y Arte, 5(2), 24-30.

Butler, J. (1999). Performativity's Social Magic. En: R. Shusterman. (Ed.). Bourdieu: A Critical Reader (pp. 113-128). New Jersey: Wiley.

Butler, J. (2009). Performatividad, precariedad y políticas sexuales. AIBR. Revista de Antropología Iberoamericana, 4(3), 321-336.

Chaparro, A. (2006). La premodernidad. Sujetos, sujeciones y procesos de subjetivación. Cuestiones de Filosofía, 8, 15-29.

De Certeau, M. (2000). La invención de lo cotidiano. Artes de Hacer (Vol. I). México: Universidad Iberoamericana.

Deleuze, G. (1991). A Philosophical Concept... En: J.-L. Nancy, E. Cadava, \& P. Connor. (Eds.). Who Comes After the Subject? (pp. 94-96). New York: Routledge.

Foucault, M. (2013). La tecnología política de los individuos. En: E. Castro (Ed.) Michel Foucault. La inquietud por la verdad. Escritos sobre la sexualidad y el sujeto (pp. 239-255). Buenos Aires: Siglo XXI.

Lacan, J. (2007). Escritos. Madrid: Siglo XXI.

Maffesoli, M. (2007). En el crisol de las apariencias. México: Siglo XXI.

Nancy, J.-L. (1991). Introduction. En: J.-L. Nancy, E. Cadava, \& P. Connor. (Eds.). Who Comes After the Subject? (pp. 1-9). New York: Routledge. 
Vives, G. (2016, julio 6). 7 vestidos para 90 días de verano. Vogue España [online]. Recuperado de: http://www.vogue.es/moda/tendencias/galerias/ vestidos-verano-vogue-gigi-vives/12889/image/1139873

Žižek, S. (2007). El espinoso sujeto. Buenos Aires: Paidós.

Žižek, S. (2011). El acoso de las fantasias. Madrid: Akal. 